\title{
Audit Infrastruktur Aplikasi Pelayanan Publik Pemerintah Kota Denpasar
}

\author{
Tjokorda Istri Ratih Kumbara Dewi ${ }^{1}$ Linawati $^{2}$, I Made Oka Widyantara ${ }^{3}$
}

\begin{abstract}
One of the main functions of Communications and Information Departmnent of Denpasar City is a public service application infrastructure management. Public services such as settlement services in Denpasar using the application Administration Information System (SIAK) which includes the manufacture of ID Card, Family Registers, and a birth certificate. To improve the quality of infrastructure management while improving the quality of public services, then conducted an internal evaluation in the form of audit in the management of public service application infrastructure so that the manager can do the planning for improvement and development of infrastructure has been built. Audits carried out by using the COBIT 4.1 framework as controls. Based on the results of audits using COBIT 4.1 Maturity Model, obtained level of maturity in the process AI3 (Obtaining and Maintaining Infrastructure Technology) which is located on level 3 (defined). For an objective assessment, the maturity level is between level 3 (defined) and level 4 (managed and measurable) that is equal to 3.53. Recommendations are given in stages based on the level of maturity that is obtained from the evaluation that maturity level 3 (defined) to be upgraded to a maturity level 4 (managed and measurable), then increased again towards the ideal maturity level 5 (optimized).
\end{abstract}

Intisari - Salah satu Tugas Pokok dan Fungsi utama Dinas Komunikasi dan Informatika Kota Denpasar adalah sebagai pengelola infrastruktur aplikasi pelayanan publik di Pemerintah Kota Denpasar. Pelayanan publik berupa pelayanan kependudukan di Kota Denpasar menggunakan aplikasi Sistem Informasi Administrasi Kependudukan (SIAK) yang meliputi pembuatan KTP, KK, dan Akta Kelahiran. Untuk meningkatkan kualitas pengelolaan infrastruktur sekaligus meningkatkan kualitas pelayanan publik, maka dilakukan suatu evaluasi internal berupa audit dalam pengelolaan infrastruktur aplikasi pelayanan publik agar pihak pengelola dapat melakukan perencanaan untuk perbaikan serta peningkatan dan pengembangan infrastruktur yang telah dibangun. Audit dilakukan dengan menggunakan COBIT 4.1 sebagai kerangka kerja kontrol. Berdasarkan hasil audit dengan menggunakan Maturity Model COBIT 4.1, diperoleh tingkat kematangan pada proses AI3 (Mendapatkan dan Memelihara Infrastruktur Teknologi) yaitu berada pada level 3 (defined). Untuk penilaian secara objektif, tingkat kematangan berada diantara level 3 (defined) dan level 4 (managed and measurable) yaitu sebesar 3,53.

${ }^{1}$ Mahasiswa, Magister Teknik Elektro Universitas Udayana, Jl PB. Sudirman, Denpasar Bali. Tel. 0361223797 fax: 0361 247962; e-mail:cokisratih@gmail.com

${ }^{2}$ Dosen Teknik Elektro dan Komputer Universitas Udayana, Kampus Bukit Jimbaran, Badung Bali. 80361, Tel. 0361703315 fax:0361 703315; e-mail:linawati@unud.ac.id

${ }^{3}$ Dosen Teknik Elektro dan Komputer Universitas Udayana, Kampus Bukit Jimbaran, Badung Bali. 80361, Tel. 0361703315 fax: 0361 703315; e-mail:oka.widyantara@unud.ac.id)
Rekomendasi diberikan secara bertahap berdasarkan tingkat kematangan yang diperoleh dari hasil evaluasi yaitu tingkat kematangan 3 (defined) untuk dapat ditingkatkan ke tingkat kematangan 4 (managed and measurable), kemudian ditingkatkan lagi menuju tingkat kematangan ideal yaitu 5 (optimized).

Kata Kunci-Audit, Infrastruktur, Tingkat kematangan, COBIT 4.1

\section{PENDAHULUAN}

Pemerintah Kota Denpasar sebagai salah satu institusi pemerintahan daerah telah menerapkan e-government sejak tahun 2005 melalui pembangunan infrastruktur TIK secara bertahap. Infrastruktur TIK yang dibangun oleh Dinas Komunikasi dan Informatika saat ini sudah menghubungkan seluruh Satuan Kerja Perangkat Daerah (SKPD) ke jaringan intranet maupun internet dan menjadi tulang punggung dalam setiap aktivitas komunikasi data dan informasi melalui aplikasi-aplikasi baik yang dapat diakses melalui internet maupun intranet. Sebagai penyedia infrastruktur aplikasi, kinerja layanan aplikasi yang digunakan baik oleh internal lingkungan Pemerintah Kota Denpasar maupun masyarakat melalui akses internet sangat dipengaruhi oleh pengelolaan infrastruktur oleh Dinas Komunikasi dan Informatika Kota Denpasar. Ukuran tingkat kemampuan pengelolaan TIK organisasi dapat dilihat dari seberapa jauh organisasi tersebut dapat menggelar infrastrukturnya [1].

Berdasarkan Laporan pengaduan jaringan milik Dinas Komunikasi dan Informatika Kota Denpasar Tahun 2015, jumlah pengaduan gangguan jaringan oleh Dinas Catatan Sipil dan Kependudukan dan Kecamatan sebanyak 35 kali pengaduan. Jika dirata-ratakan menjadi sebanyak 3 kali gangguan dalam satu bulannya. Pengelolaan infrastruktur menjadi sangat vital fungsinya karena merupakan tulang punggung jalannya berbagai aplikasi pelayanan publik. Jika infrastruktur aplikasi pelayanan publik ini mengalami permasalahan baik dari sisi pengelolaan maupun sisi kerusakan secara fisik, maka akan menghambat semua proses yang berujung kepada komplain masyarakat dan berdampak pada menurunnya tingkat kepercayaan publik.

Oleh karena itu diperlukan suatu evaluasi internal berupa audit agar pihak pengelola dapat melakukan perencanaan untuk perbaikan serta peningkatan dan pengembangan infrastruktur yang telah dibangun. Penelitian ini membahas mengenai bagaimana tingkat kematangan tata kelola infrastruktur aplikasi pelayanan publik di Pemerintah Kota Denpasar dengan menggunakan kerangka kerja COBIT versi 4.1. Audit dilakukan pada infrastruktur aplikasi pelayanan publik yaitu pada infrastruktur aplikasi SIAK (Sistem Informasi Administrasi Kependudukan) pada domain AI3 
yaitu Mendapatkan dan Memelihara Infrastruktur sesuai Tupoksi utama Dinas Komunikasi dan Informatika Kota Denpasar.

\section{RELATED WORKS}

A. State Of The Art Review

Berbagai penelitian audit dalam bidang TIK dengan menggunakan Framework COBIT telah banyak dilakukan. Burdefira [2] melakukan audit untuk mengetahui tingkat kematangan tata kelola TIK serta dapat menghasilkan dokumen tata kelola TIK pada Pemerintah Kota Padang. Audit yang dilakukan meliputi penentuan proses-proses TIK yang kritikal melalui identifikasi dan pemetaan proses TIK Pemerintah Kota Padang dengan proses TIK pada COBIT, pengukuran tingkat kematangan dari proses-proses tersebut melalui penyebaran kuisioner, dan pemberian rekomendasi atas perolehan tingkat kematangan. Hasil dari penelitian ini yaitu nilai tingkat kematangan tata kelola TIK pada pemerintah Kota Padang masih berada di bawah 1.00.

Krisanthi dkk [3] melakukan audit pada aplikasi pengadaan milik universitas. Dari hasil penyebaran kuisioner, diperoleh tingkat kematangan sebesar 2,85 sedangkan level kematangan yang diharapkan sebesar 5 (optimized). Berdasarkan kesenjangan kematangan tersebut maka diperlukan strategi perbaikan yang memuat langkah-langkah yang diperlukan untuk mencapai tingkat kematangan yang diinginkan.

Terdapat audit salah satu proses TIK spesifik seperti yang dilakukan oleh Megawati dan Amrullah [4] pada PT BRI dengan tujuan perbaikan pada proses pengelolaan kualitas sistem informasi. Pengukuran tingkat kematangan dilakukan pada domain Plan and Organise yaitu pada proses pengelolaan kualitas (PO8). Dihasilkan tingkat kematangan berada pada level 3 (defined). Hasil dari pengukuran ini digunakan sebagai acuan dalam pemberian rekomendasi perbaikan proses pengelolaan kualitas sistem informasi.

Hal yang sama juga dilakukan oleh Hermanto dan Ricoida [5] yaitu melakukan audit pada domain yang spesifik yaitu pada domain Deliver and Support dan Monitoring and Evaluateuntuk mengukur pemanfaatan TIK yang telah diterapkan pada PT.SMI. Berdasarkan hasil penyebaran kuisioner, diperoleh tingkat kematangan berada pada level 3 dimana tingkat kematangan ini belum memenuhi tingkat kematangan yang diharapkan perusahaan.

Dari penelitian-penelitian yang sudah dilakukan, belum dilakukan penilaian secara objektif dengan mengumpulkan bukti proses-proses TIK yang sudah berjalan apakah sudah sesuai dengan tingkat kesetujuan pernyataan dalam kuisioner.Pada penelitian-penelitian sebelumnya, kuisioner untuk mengukur tingkat kematangan diisi oleh responden berdasarkan pemetaan RACI chart atau pegawai yang berhubungan dengan pengelolaan TIK. Berbeda dengan penelitian sebelumnya, pada penelitian ini akan dilakukan juga pengisian kuisioner secara objektif oleh peneliti dengan mengumpulkan bukti-bukti berupa dokumen pendukung untuk memastikan kebenaran pilihan tingkat kesetujuan. Hal ini dilakukan sebagai bahan perbandingan apakah pengisian

Tjokorda Istri Ratih Kumbara Dewi: Audit Infrastruktur... kuisioner yang dilakukan oleh responden sudah dapat merepresentasikan keadaan yang sebenarnya.

\section{B. Pengelolaan Infrastruktur Aplikasi Pelayanan Publik}

Untuk memastikan penggunaan TIK benar-benar mendukung tujuan penyelenggaraan pemerintahan, dengan memperhatikan efisiensi penggunaan sumber daya dan pengelolaan risiko, diperlukan Good Governance terkait dengan TIK yang disebut sebagai Tata Kelola TIK. Prinsip dasar pondasi bangunan Tata Kelola TIK Nasional mendasari model dan tingkat kedalaman implementasi model [6].

Salah satu tupoksi utama Dinas Komunikasi dan Informatika Kota Denpasar yaitu dalam hal pengelolaan infrastruktur jaringan untuk seluruh SKPD di Kota Denpasar. Hal ini meliputi perencanaan, penyediaan, serta pemeliharaan infrastruktur jaringan. Pengelolaan infrastruktur ini ditangani oleh Bidang Piranti Keras dengan struktur organisasi yang dapat dilihat pada Gambar 1 berikut :

\section{Gambar 1: Struktur Organisasi Bidang Piranti Keras dan Jaringan}

Seluruh SKPD di Pemerintah Kota Denpasar saat ini sudah terhubung ke jaringan wide area network (WAN), dengan total 40 titik yang tersebar dengan network operation centre (NOC) berada di Gedung Graha Sewaka Dharma. Media transmisi yang digunakan adalah wireless dan fiber optic sebagai jaringan backbone. Pada Gambar 2 dapat dilihat topologi infrastruktur aplikasi SIAK. Aplikasi SIAK yang diakses oleh operator 4 Kecamatan ini bersifat client server dengan platform website dimana server berada di kantor Dinas Kependudukan dan Catatan Sipil Kota Denpasar.

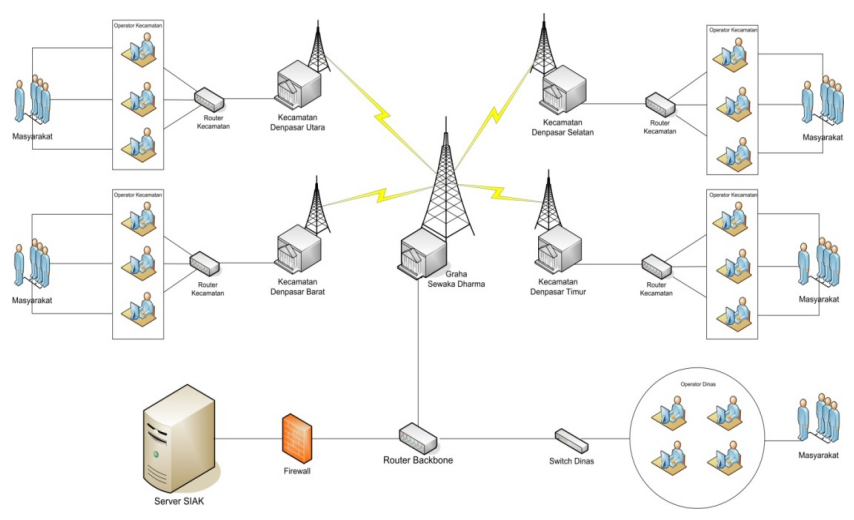

Gambar 2 : Topologi Jaringan Aplikasi SIAK

p-ISSN:1693 - 2951; e-ISSN: 2503-2372

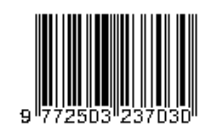




\section{C.COBIT4.1}

Control Objectives for Information and Related Technology (COBIT), merupakan salah suatu tata kelola (Framework) yang dikembangkan oleh Information Systems Audit and Control Association (ISACA) dan IT Governance Institute (ITGI). COBIT mencakup proses model yang dikembangkan untuk membantu perusahaan/organisasi dalam pengelolaan sumber daya teknologi informasi komunikasi (TIK). COBIT 4.1 terdiri atas 4 domain tahapan pengelolaan TIK : Planning and Organise, Acquisition \& Implementation, Delivery \& Support, dan Monitoring and Evaluation dan mengelompokkan semua aktivitas bisnis yang terjadi dalam organisasi menjadi 34 proses yang terbagi ke dalam empat buah domain proses tersebut [7].

\section{Maturity Model}

Salah satu alat pengukuran dari kinerja suatu sistem teknologi informasi adalah model kematangan (maturity model). Model ini didasari pada metode evaluasi organisasi sehingga dapat mengevaluasi sendiri dari level 0 (Nonexistent) hingga level 5 (Optimized).

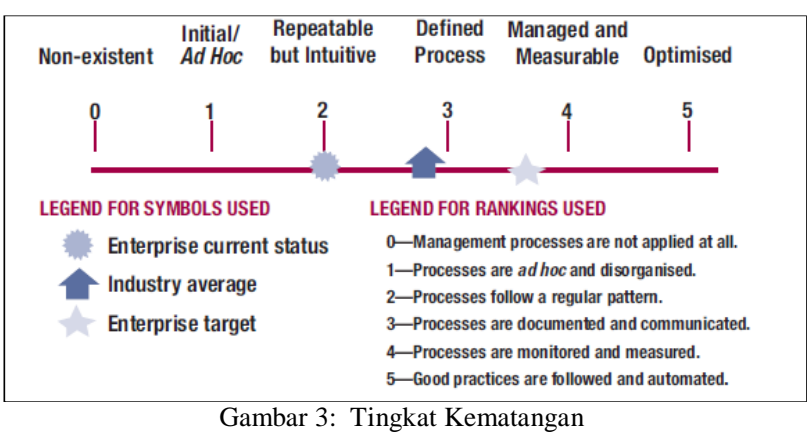

Keterangan masing-masing level sebagai berikut:

- Non-eksistent $(0=$ Management processes are not applied at all)

Perusahaan sama sekali tidak perduli terhadap pentingnya teknologi informasi agar dikelola secara baik oleh manajemen.

- Adhoc ( $1=$ Processes are ad hoc and disorganized) Perusahaan melakukan penerapan dan implementasi teknologi informasi secara reaktif sesuai dengan kebutuhan-kebutuhan mendadak yang ada, tanpa didahului dengan perencanaan. Pendekatan kepada pengelolaan proses tidak terorganisasi.

- Repeatable ( 2 = Processes/allow a regular pattern)

Terdapat pola berulang yang dilakukan dalam manajemen terkait aktivitas tata kelola teknologi informasi, namun keberadaannya belum terdefinisi secara baik dan formal sehingga masih bersifat tidak konsisten. Tidak terdapat pelatihan formal dan tanggung jawab diserahkan kepada masing-masing individu.

- Defined (3 = Processes are documented and communicated)

Terdapat prosedur baku formal dan tertulis yang telah disosialisasikan ke segenap jajaran manajemen dan karyawan untuk dipatuhi dan dikerjakan dalam aktivitas sehari-hari. Prosedur distandarisasi, didokumentasikan dan kemudian dikomunikasikan melalui pelatihan.

Managed (4 = Processes are monitored and measured) Perusahaan telah memiliki sejumlah indikator atau ukuran kuantitatif yang dijadikan sebagai sasaran maupun obyektif kinerja setiap penerapan aplikasi teknologi informasi yang ada. Manajemen mengawasi dan mengukur kepatutan terhadap prosedur dan mengambil tindakan jika proses tidak dapat dikerjakan secara efektif.

Optimized $(5=$ Best practices are followed and automated)

Perusahaan telah menerapkan tata kelola teknologi informasi yang mengacu pada best practice. Teknologi informasi digunakan sebagai cara terintegrasi untuk mengotomatisasi alur kerja, penyediaan alat untuk peningkatan kualitas dan efektifitas serta membuat perusahaan cepat beradaptasi.

\section{METODELOGI}

Analisis penelitian ini menggunakan metode deskriptif kualitatif dengan penyebaran kuisioner. Kuesioner terdiri atas pernyataan-pernyataan sesuai proses TIK terkait yang dibuat dengan menggunakan acuan COBIT 4.1 Maturity Model. Responden kuisioner merupakan pemetaan RACI chart ke dalam struktur organisasi Dinas Kominfo Kota Denpasar yang dapat dilihat pada Tabel I.

TABEL I

PEMETAAN RACI CHART

\begin{tabular}{|l|l|}
\hline \multicolumn{1}{|c|}{ RACI Chart } & \multicolumn{1}{c|}{ Fungsional Organisasi } \\
\hline $\begin{array}{l}\text { Chief Financial Officer } \\
\text { (CFO) }\end{array}$ & Kasubag Keuangan \\
\hline $\begin{array}{l}\text { Chief Information Officer } \\
\text { (CIO) }\end{array}$ & Sekretaris Dinas \\
\hline Business Process Owner & $\begin{array}{l}\text { Kepala Dinas Kependudukan } \\
\text { dan Catatan Sipil }\end{array}$ \\
\hline Head Operations & $\begin{array}{l}\text { Kepala Seksi Sosialisasi dan } \\
\text { Pemeliharaan PKJ }\end{array}$ \\
\hline Chief Architect & $\begin{array}{l}\text { Kepala Seksi Perencanaan dan } \\
\text { Analisa PKJ }\end{array}$ \\
\hline Head Development & Kepala Bidang Bina Program \\
\hline Head IT Administration & Kasubag Umum \\
\hline
\end{tabular}

Analisa dilakukan dengan 3 tahap, yaitu :

1. Penilaian Tingkat Kematangan

Dihitung level kematangan proses TIK terpilih berdasarkan data hasil pengisian kuesioner. Kuisioner terdiri dari pernyataan dalam COBIT 4.1 yang dipecah menjadi pernyataan-pernyataan yang memiliki nilai/bobot sesuai dengan tingkat kesetujuannya [8]. Pada penelitian ini digunakan 5 level tingkat kesetujuan sebagai berikut :

TABEL II

NILAI TINGKAT KESETUJUAN

\begin{tabular}{|l|c|}
\hline Agreement with Statement & Compliance Value \\
\hline Sangat tidak Setuju & 0 \\
\hline Kurang setuju & 0,25 \\
\hline Cukup setuju & 0,50 \\
\hline Setuju & 0,75 \\
\hline Sangat setuju & 1 \\
\hline
\end{tabular}


Langkah perhitungan tingkat kematangan [8] dijelaskan sebagai berikut:

a. Menghitung compliance masing-masing level Tingkat compliance masing-masing level diperoleh dari hasil pembagian nilai compliance per level dengan jumlah pernyataan per level sesuai dengan Persamaan1 sebagai berikut :

$$
A=\frac{C}{B}
$$

b. Melakukan normalisasi tingkat compliance

Setelah tingkat compliance masing-masing level telah diperoleh, langkah selanjutnya adalah melakukan normalisasi (D) dengan nilai masingmasing tingkat compliance dengan total nilai compliance sesuai Persamaan 2.

$$
D=\frac{A}{\sum_{i=0}^{5} A}
$$

c. Menghitung nilai tingkat kematangan

Setelah nilai compliance masing-masing level telah dinormalisiasi, maka selanjutnya menghitung kontribusi masing-masing level dengan Persamaan 3 sebagai berikut :

$E=i * D$

Setelah nilai kontribusi masing-masing level diperoleh dan dijumlahkan, maka didapatkan nilai tingkat kematangan atau Maturity sesuai dengan Persamaan 4.

$$
F=\sum_{i=0}^{5} E
$$

Keterangan :

$A=$ Tingkat compliance masing-masing level

$C=$ Nilai compliance per level

$B=$ Jumlah pernyataan per level

$D=$ Normalisasi tingkat compliance per level

$i=$ Tingkatan Level kematangan

$E=$ Nilai kontribusi per level

$F=$ Tingkat kematangan (maturity)

\section{Analisa Kesenjangan}

Pada tahap ini dilakukan analisis kesenjangan tingkat kematangan yang diperoleh (tingkat kematangan kondisi eksisting) dengan tingkat kematangan yang diharapkan.

\section{Penyusunan Rekomendasi}

Berdasarkan kesenjangan kematangan tersebut, kemudian dilakukan analisis penyusunan rekomendasi.

\section{HASIL DAN PEMBAHASAN}

\section{A. Penilaian Tingkat Kematangan}

Pengadaan dan pemeliharaan infrastruktur pada Dinas Komunikasi dan Informatika Kota Denpasar dilaksanakan oleh Bidang Piranti Keras dan Jaringan sesuai tupoksinya. Anggaran biaya untuk pemeliharaan disediakan melalui kegiatan rutin yaitu Kegiatan Peningkatan Sarana dan Tjokorda Istri Ratih Kumbara Dewi: Audit Infrastruktur...
Prasarana Aparatur di Bagian Umum, sedangkan untuk pelaksanaan pemeliharaannya dilakukan oleh Bidang Piranti Keras dan Jaringan pada Seksi Sosialisasi dan Pemeliharaan Piranti Keras dan Jaringan. Terdapat pegawai yang bertanggung jawab terhadap proses pembuatan kontrak pengadaan seperti : Pejabat Pembuat Komitmen, Pejabat Pengadaan Barang Jasa, Pejabat Pelaksana Teknis Kegiatan, dan Tim Pemeriksa Hasil Pekerjaan. Proses pengadaan berjalan secara formal sesuai Juknis Perpres No. 70 Tahun 2012 serta arahan dari Bagian Keuangan Setda Kota Denpasar. Dalam proses pengadaan, implementasi dan upgrade teknologi infrastruktur, suatu organisasi memerlukan perencanaan, perawatan, dan perlindungan terhadap infrastruktur yang menjamin keberlangsungan dukungan teknologi terhadap organisasi. Tingkat kematangan pada AI3 diukur dengan melihat proses perolehan dan pemeliharaan infrastruktur TIK yang terintegrasi dan terstandarisasi. Pengisian kuisioner dilakukan oleh pegawai yang terlibat dalam proses mendapatkan dan memeliharan teknologi infrastruktur sesuai dengan pemetaan RACI Chart, yaitu Kasubag Keuangan, Sekretaris, Kasi Pemeliharaan, Kasi Perencanaan, Kabid Bina Program, dan Kasubag Umum. Hasil penyebaran kuisioner dapat dilihat pada Tabel III berikut :

TABEL III

TINGKAT KEMATANGAN HASIL KUISIONER PADA PROSES AI3

\begin{tabular}{|l|c|}
\hline \multicolumn{1}{|c|}{ Pendapat } & Maturity \\
\hline Kasubag Keuangan & 3,23 \\
\hline Sekretaris & 3,55 \\
\hline Kadis Capil dan Kependudukan & 3,26 \\
\hline Kasi Pemeliharaan & 3,11 \\
\hline Kasi Perencanaan & 3,08 \\
\hline Kabid Binpro & 3,62 \\
\hline Kasubag Umum & 3,43 \\
\hline \multicolumn{2}{|c|}{ Rata-rata Maturity } \\
\hline
\end{tabular}

Berdasarkan Tabel III diatas dapat dilihat bahwa tingkat kematangan pada proses AI3 yaitu 3,33 jika dibulatkan berada pada level 3 (Defined/ ditetapkan), yang artinya :

1. Terdapat proses pengadaan dan pemeliharaan infrastruktur aplikasi pelayanan publik yang jelas, terdefinisikan, dan dipahami secara umum.

2. Terdapat proses pengadaan dan pemeliharaan infrastruktur TIK yang sesuai dengan kebutuhan aplikasi dan rencana strategis, namun belum diterapkan secara konsisten.

3. Proses pemeliharaan infrastruktur TIK sudah terjadwal dan terkoordinasi.

Pada penilaian kuisioner secara objektif, peneliti melakukan pengisian kuisioner secara objektif yang disertai dengan bukti-bukti pendukung pernyataan dalam kuisioner. Pengisian kuisioner secara objektif bertujuan untuk memberikan perbandingan penilaian terhadap obyek yang p-ISSN:1693 - 2951; e-ISSN: 2503-2372 
diteliti.Berdasarkan hasil perhitungan tingkat kematangan, diperoleh tingkat kematangan pada proses Mendapatkan dan Memelihara Infrastruktur Teknologi (AI3) yaitu berada diantara level 3 (defined) dan level 4 (managed and measurable) yaitu sebesar 3,53, dimana terdapat proses pengadaan dan pemeliharaan infrastruktur aplikasi pelayanan publik yang jelas, terdefinisikan, dan dipahami secara umum. Proses pengadaan dan pemeliharaan infrastruktur sudah sesuai dengan kebutuhan aplikasi dan rencana strategis, namun belum diterapkan secara konsisten. Pemeliharaan dilakukan berdasarkan pengaduan dari SKPD. Proses pengadaan dan pemeliharaan infrastruktur dikembangkan agar dapat masih berfungsi pada kondisi yang tidak ideal. Infrastruktur sudah cukup mensupport semua aplikasi yang ada. Terdapat kesadaran bahwa tanpa adanya infrastruktur, semua aplikasi tidak akan dapat berjalan.

Dilakukan perbandingan hasil tingkat kematangan terhadap pengisian kuisioner responden dengan pengisian kuisioner secara objektif sebagai perbandingan bahwa pengisian kuisioner yang dilakukan oleh responden sudah merepresentasikan keadaaan yang sebenarnya. Hasil perbandingannya dapat dilihat pada Tabel 4 berikut ini.

TABEL IV

.PERBANDINGAN TINGKAT KEMATANGAN (MATURITY)

\begin{tabular}{|c|l|c|c|}
\hline \multicolumn{2}{|c|}{ Proses } & $\begin{array}{c}\text { Maturity } \\
\text { Subjektif }\end{array}$ & $\begin{array}{c}\text { Maturity } \\
\text { Objektif }\end{array}$ \\
\hline AI3 & $\begin{array}{l}\text { Mendapatkan dan Memelihara } \\
\text { Infrastruktur Teknologi }\end{array}$ & 3,33 & 3,53 \\
\hline
\end{tabular}

Berdasarkan Tabel IV dapat dilihat bahwa rata-rata tingkat kematangan pengisian kuisioner oleh responden sebesar 3,33sedangkan rata-rata pengisian kuisioner secara objektif sebesar 3,53. Terdapat selisih yang tidak signifikan yaitu sebesar 0,2. Perbedaan perolehan tingkat kematangan terjadi karena pada saat pengisian kuesioner, responden tidak mencari dan menyertakan bukti-bukti pendukung pilihan jawaban. Kesetujuan pada pernyataan dalam kuesioner dipilih berdasarkan kebiasaan dan ingatan.

\section{B. Analisa Kesenjangan}

Analisa kesenjangan dilakukan untuk menentukan langkah dan upaya yang harus dilakukan Dinas Komunikasi dan Informatika Kota Denpasar untuk mencapai tingkat kematangan yang diinginkan. Tingkat kematangan yang diinginkan oleh pihak pengelola yaitu pada level 5 (optimized).

Tabel V berikut ini memperlihatkan kesenjangan kematangan (gap) antara tingkat kematangan saat ini (Current Maturity) dengan tingkat kematangan yang diinginkan (Expected Maturity).

Pada Tabel V dapat dilihat gap kematangan yang terjadi pada pengelolaan infrastruktur aplikasi pelayanan publik. Berdasarkan evaluasi yang telah dilakukan, gap yang terjadi untuk mencapai tingkat kematangan 4 disebabkan Dinas Komunikasi dan Informatika Kota Denpasar
TABEL V

KESENJANGAN KEMATANGAN

\begin{tabular}{|l|c|c|c|}
\hline \multicolumn{1}{|c|}{ Proses } & \multirow{2}{*}{$\begin{array}{c}\text { Current } \\
\text { Maturit }\end{array}$} & $\begin{array}{c}\text { Expected } \\
\text { Maturity }\end{array}$ & $\begin{array}{c}\text { Expected } \\
\text { Maturity }\end{array}$ \\
\hline $\begin{array}{l}\text { Mendapatkan dan } \\
\begin{array}{l}\text { Memelihara } \\
\text { Infrastruktur Teknologi } \\
\text { (AI3) }\end{array}\end{array}$ & 3,33 & 0,67 & $\mathbf{5}$ \\
\hline
\end{tabular}

belum melakukan pengukuran terhadap waktu dan biaya yang diperlukan untuk mencapai tingkat level integrasi, skalabititas, dan fleksibilitas yang dinginkan.Sedangkan gap kematangan untuk mencapai level 5 terjadi karena belum adanya arsitektur teknologi infrastruktur dan belum dilakukan proses pengadaan dan pemeliharaan infrastruktur yang sesuai dengan arsitektur tersebut. Disamping itu, proses pengadaan dan pemeliharaan infrastruktur TIK belum dilakukan secara aktif dan sesuai dengan aplikasi serta arsitektur teknologi.

\section{Rekomendasi}

Berdasarkan hasil evaluasi pengelolaan infrastruktur aplikasi pelayanan publik yang telah dilakukan, maka dilakukan pemberian rekomendasi untuk perbaikan pada prosesMendapatkan dan Memelihara Infrastruktur Teknologi (AI3). Rekomendasi diberikan secara bertahap berdasarkan tingkat kematangan terendah yang diperoleh dari hasil evaluasi yaitu tingkat kematangan 3 (defined) untuk dapat ditingkatkan ke tingkat kematangan 4 (managed and measurable), kemudian ditingkatkan lagi menuju tingkat kematangan 5 (optimized). Perbedaan kondisi tingkat kematangan saat ini dengan tingkat kematangan yang diharapkan pada proses Mendapatkan dan Memelihara Infrastruktur Teknologi (AI3) dapat dilihat pada Gambar 4.1 berikut:

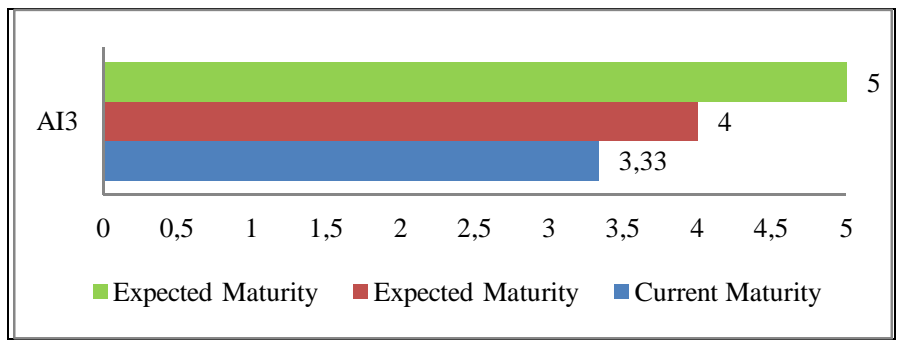

Gambar 4: Perbedaan Tingkat Kematangan

Pada Gambar 4 diatas dapat dilihat gap tingkat kematangan yang terjadi padaprosesMendapatkan dan Memelihara Infrastruktur Teknologi (AI3), sehingga rekomendasi yang diberikan untuk mencapai tingkat kematangan yang diinginkan dapat dilihat pada Tabel IV berikut : 
TABEL VI

REKOMENDASI PERBAIKAN

\begin{tabular}{|c|c|c|c|}
\hline \multirow{2}{*}{ Proses } & \multirow{2}{*}{ Rekomendasi } & \multicolumn{2}{|c|}{$\begin{array}{l}\text { Expected } \\
\text { Maturity }\end{array}$} \\
\hline & & 4 & 5 \\
\hline AI3 & $\begin{array}{l}\text { Hendaknya } \text { dilakukan } \\
\text { pengukuran terhadap waktu } \\
\text { dan biaya yang diperlukan } \\
\text { untuk mencapai tingkat level } \\
\text { integrasi, skalabititas, dan } \\
\text { fleksibilitas yang dinginkan. }\end{array}$ & $\sqrt{ }$ & \\
\hline
\end{tabular}

TABEL VI

REKOMENDASI PERBAIKAN

\begin{tabular}{|l|l|l|l|}
\hline \multirow{5}{*}{ Proses } & \multicolumn{1}{|c|}{ Rekomendasi } & \multicolumn{2}{|c|}{$\begin{array}{c}\text { Expected } \\
\text { Maturity }\end{array}$} \\
\cline { 2 - 3 } & & $\mathbf{4}$ & $\mathbf{5}$ \\
\hline AI3 & $\begin{array}{l}\text { Perlu dibuat suatu arsitektur } \\
\text { teknologi infrastruktur dan } \\
\text { dilakukan proses pengadaan } \\
\text { dan pemeliharaan } \\
\text { infrastruktur yang sesuai } \\
\text { dengan arsitektur tersebut. }\end{array}$ & & \\
\hline & $\begin{array}{l}\text { Hendaknya proses pengadaan } \\
\text { dan pemeliharaan } \\
\text { infrastruktur TIK dilakukan } \\
\text { secara aktif dan sesuai dengan } \\
\text { aplikasi serta arsitektur } \\
\text { teknologi. }\end{array}$ & \\
\hline
\end{tabular}

\section{KESIMPULAN}

Berdasarkan hasil evaluasi pengelolaan infrastruktur aplikasi pelayanan publik pada Dinas Komunikasi dan Informatika Kota Denpasar, diperoleh tingkat kematangan pada prosesMendapatkan dan Memelihara Infrastruktur Teknologi (AI3) yaitu berada pada level 3 (defined). Untuk penilaian secara objektif, tingkat kematangan berada diantara level 3 (defined) dan level 4 (managed and measurable) yaitu sebesar 3,53. Perbedaan perolehan tingkat kematangan terjadi karena kesetujuan responden pada pernyataan dalam kuesioner dipilih berdasarkan kebiasaan dan ingatan. Tingkat kematangan yang dinginkan oleh pihak pengelola yaitu pada level 5 (optimized). Untuk mengatasi kesenjangan antara tingkat kematangan saat ini (current maturity) dengan tingkat kematangan yang diinginkan (expected maturity) maka diberikan rekomendasi yaitu : hendaknya dilakukan pengukuran terhadap waktu dan biaya yang diperlukan untuk mencapai tingkat level integrasi, skalabititas, dan fleksibilitas yang dinginkan, serta perlu dibuat suatu arsitektur teknologi infrastruktur dan dilakukan proses pengadaan dan pemeliharaan secara aktif yang sesuai dengan arsitektur tersebut.

\section{REFERENSI}

[1] P. Weill and J. W. Ross, IT Governance : How Top Performers Manage IT Decision Rights for Superior Result. Harvard Business Press, 2004.

[2] Burdefira, "Evaluasi Terhadap Implementasi Tata Kelola Teknologi Informasi Berdasarkan Framework COBIT pada Pemerintah Kota Padang”. Program Studi Chief Information Officer, Fakultas Teknik Universitas Negeri Padang, 2013.

[3] G. A. T. Krisanthi, I. M. Sukarsa, P. A. Bayupati, "Governance Audit Of Application Procurement Using COBIT Framework". Journal of Theoretical and Applied Information Technology. Vol.59 No.2, 2014.

[4] Megawati dan Amrullah, "Evaluasi Tingkat Kematangan Teknologi Informasi Dengan Menggunakan Model Maturity Level COBIT 4.1 (Studi Kasus PT. BRI Cabang Bangkinang)". Jurnal Sains, Teknologi dan Industri. Vol.12 No. 1, Desember 2014.

[5] Hermanto dan Ricoida, "Analisis Pengukuran Tingkat Kematangan Menggunakan Kerangka COBIT 4.1 (Studi Kasus: PT. SMI)”, dalam Seminar Nasional Sistem Informasi Indonesia, 22 September 2014.

[6] Peraturan Menteri Komunikasi dan Informatika No. 41/PER/MEN.KOMINFO/11/2007 tentang Panduan Umum Tata Kelola Teknologi Informasi dan Komunikasi Nasional.

[7] ITGI, COBIT 4.1 : Framework, Control Objective, Management Guidelines, Maturity Models. United States of America : IT Governance Institute, 2007.

[8] Pederiva, A. "The COBIT Maturity Model in A Vendor Evaluation Case”, Information System Control Journal. Volume 3, 2003. 